\title{
Modelling of a Variable Refrigerant Flow System in EnergyPlus for Building Energy Simulation in an Open Building Information Modelling Environment
}

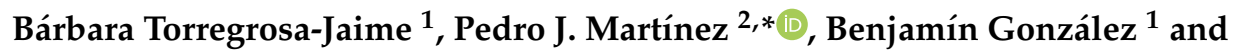 \\ Gaspar Payá-Ballester ${ }^{1}$ \\ 1 CYPE Ingenieros, S.A., Avda. Eusebio Sempere, 5, 03003 Alicante, Spain; \\ barbara.torregrosa@cype.com (B.T.-J.); benjamin.gonzalez@cype.com (B.G.); gaspar.paya@cype.com (G.P.-B.) \\ 2 Departamento de Ingeniería Mecánica y Energía, Universidad Miguel Hernández, Avda. de la Universidad, \\ s/n, 03202 Elche, Spain \\ * Correspondence: pjuan.martinez@umh.es; Tel.: +34-966658566
}

Received: 25 November 2018; Accepted: 19 December 2018; Published: 21 December 2018

\begin{abstract}
Variable refrigerant flow (VRF) systems are one possible tool to meet the objective that all new buildings must be nearly zero-energy buildings by 31 December 2020. Building Information Modelling (BIM) is a methodology that centralizes building construction project information in a digital model promoting collaboration between all its agents. The objectives of this work were to develop a more precise model of the VRF system than the one available in EnergyPlus version 8.9 (US Department of Energy) and to study the operation of this system in an office building under different climates by implementing the building energy simulation in an Open BIM workflow. The percentage deviation between the estimation of the VRF energy consumption with the standard and the new model was $6.91 \%$ and $1.59 \%$ for cooling and heating respectively in the case of Barcelona and $3.27 \%$ and $0.97 \%$ respectively in the case of Madrid. The energy performance class of the analysed building was A for each climatic zone. The primary energy consumption of the office building equipped with the VRF system was of $65.8 \mathrm{kWh} /\left(\mathrm{m}^{2} \cdot \mathrm{y}\right)$ for the Mediterranean climate of Barcelona and $72.4 \mathrm{kWh} /\left(\mathrm{m}^{2} \cdot \mathrm{y}\right)$ for the Continental climate of Madrid.
\end{abstract}

Keywords: NZEB; VRF; EnergyPlus; Open BIM; office building

\section{Introduction}

In Spain, 31.1\% of the final energy consumption takes place in buildings [1]. The 2010 Energy Performance of Buildings Directive (EPBD) [2] is the European Union's (EU) main legislation covering the reduction of energy consumption and the use of energy from renewable sources in the buildings sector. The objective that all new buildings must be nearly zero-energy buildings by 31 December 2020 is established in article 9 of the EPBD.

The EPBD lays down requirements as regards building elements that form part of the building envelope when they are retrofitted or replaced and technical building systems whenever they are installed, replaced or upgraded. The architectural, engineering and construction (AEC) industry is increasingly focusing its attention on the building envelope as part of the Heating, Ventilating and Air Conditioning (HVAC) system [3]. An integrated approach between architects and engineers can reduce heating and cooling loads.

The EPDB also states in its Article 6 that high-efficiency alternative systems such as heat pumps should be considered and taken into account. VRF heat pumps are specified for any type of commercial construction projects that require high flexibility. Buildings with diverse, multiple zones requiring 
individual control (office buildings, schools, hotels) are all good candidates [4]. VRF systems were reported as one of three most efficient systems when comparing different technologies installed in Europe, as well as one of the systems with the highest cooled floor area in commercial buildings such as offices and hotels [5].

As a recommendation, the EU provides reference intervals for primary energy consumption $\left(\mathrm{kWh} / \mathrm{m}^{2} / \mathrm{y}\right)$ for different climates [6]. The characterization of the climatic zones can suggest the suitability of certain technologies in the design of buildings [7].

VRF systems, usually condensed by air are located mainly in climatic zones characterized by mild outdoor dry-bulb temperatures (although current technology allows the use of these heat pumps in more severe climatic conditions). However, heat pumps driven by other energy sources could be more suitable for different climatic conditions such as geothermal heat pumps for the climatic conditions of Northern Europe because the soil can provide a higher temperature for heating and lower temperature for cooling than air $[8,9]$.

High-performance buildings increasingly emphasize occupant thermal comfort. This is determined by thermal indoor conditions (dry-bulb temperature, humidity, air velocity and radiant temperature), combined with occupant activity and clothing. The selection of a design dry-bulb temperature involves both comfort and energy considerations. A relative high design cooling condition $\left(26^{\circ} \mathrm{C}\right)$ may help conserve energy; while a lower one $\left(22^{\circ} \mathrm{C}\right)$ may maximize the number of satisfied occupants. Systems that perform efficiently at part-load (VRF) can mitigate the higher energy consumption of this last option.

Aynur et al. [10] compared a variable air volume (VAV) system and a variable refrigerant flow (VRF) system in terms of energy consumption and thermal comfort for an office building. The VRF system provided high energy savings because of its high part load efficiency while keeping indoor dry-bulb temperature at its design value. As regards the VAV system, there was a trade-off between the energy consumption and the indoor temperature control. It was observed that the indoor temperature could not be maintained properly without the VAV reheat boxes. If the VAV reheat boxes were used, then an energy consumption penalty up to $65.8 \%$ was obtained.

Raustad [11] developed the VRF heat pump computer model included with the U.S. Department of Energy's EnergyPlus building energy simulation software [12]. As will be explained in detail in Section 2, this computer model is an equation-fit model based on curves generated from manufacturer's performance data. Raustad indicates in his work that given the operational complexities of VRF systems, the developed model may have shortcomings that require further research such as the performance of the VRF system at partial load.

Sharma and Raustad [13] compared daily energy consumption measured in a U.S. national lab test facility with that predicted by the VRF model implemented in EnergyPlus. They found that measured and predicted data were mostly in good agreement $( \pm 25 \%)$ with some discrepancies at low energy consumption.

Hong et al. [14] developed a VRF system model for EnergyPlus with component models based on physics, needing inputs such as the bypass factor of the indoor and outdoor units. They used experimental measurements of 17 typical cooling days and 10 typical heating days for model validation. They also used those measurements to test the accuracy of the Raustad's VRF model (EnergyPlus version 7.2) finding that in terms of the daily energy consumption, the errors of the simulated results were beyond the $\pm 10 \%$ threshold.

Although both VRF models are available in EnergyPlus, the System Curve based Model (VRF-SysCurve) is the most used, maybe because manufacturers do not usually provide data to support the Physics based Model (VRF-FluidTCtrl) updated at EnergyPlus version 8.4.

The VRF-SysCurve model was used to compare the performance of VRF heat pump and rooftop variable air volume (RTU-VAV) systems in 16 different U.S. climate zones [15]. It was found that the annual final energy savings of VRF over the RTU-VAV systems for an office building were in the range of $14 \%$ to $39 \%$, being the cooling energy savings less than heating energy savings. 
Yu et al. [16] also compared the performance of VRF and VAV systems in office buildings in China. They found that VRF systems consumed up to $70 \%$ less cooling energy than VAV systems and explained these savings in terms of the operation of both systems that resulted in fewer working hours for the VRF systems.

Kanni-Sanchez et al. [17] studied the performance of a heat recovery VRF system in an office building in Ontario and concluded that the dimensioning of the outdoor units determines the working part load ratios of the system and therefore its energy consumption.

Kim et al. [18] also used the Raustad's model to study the performance of a VRF system with a dedicated outdoor air system (DOAS) for a small office building. After a proper calibration of the model, it reasonably predicted the performance of the actual system. This calibration implied a modification of the EnergyPlus (version 8.1) source code.

Building Information Modelling (BIM) is a methodology for the creation and management of a building construction project that promotes collaboration between all its agents [19]. Its objective is to centralize all project information in a digital information model ensuring consistency and effectiveness along the building life cycle [20]. The BIM methodology is based on the use of open standards, such as the IFC, which serves as a format for exchanging data between agents, processes and applications.

During the last decade, the BIM methodology has been implemented progressively in different countries, being for some of them a priority objective of its Public Administrations, which have imposed or valued its use in public works, following the recommendation of the European Directive of Public Contracting 2014/24/EU [21]. Among the benefits provided by this methodology is the improvement of the ability to simulate building energy usage and potential carbon emission reductions [22].

In Spain, a certificate of energy performance is a legal requirement for buildings when they are sold or rented. The Energy Performance Certificate provides details about the energy performance of the building and what can be done to improve it. This certificate has been implemented in most of the Member States in order to drive the market towards NZEB.

The characteristics of the building and the HVAC system should be input data for a dynamic simulation software to check the Building Energy Codes and obtain the Energy Performance Certificate. EnergyPlus [12] is used in many countries for energy performance evaluation and certification of buildings.

The definition of a precise building model in EnergyPlus is a complex task, since you need to know and treat a large number of data in order to accurately reproduce its behaviour. EnergyPlus has been mostly used for research due to the complexity and time requirement. Now it is being introduced into the architectural, engineering and construction (AEC) industry by using appropriate interfaces. The automation of this process is another reason for the adoption of the Open BIM methodology.

The first objective of this work was to develop a more precise model of the VRF HVAC system than the one available in EnergyPlus version 8.9 to better consider the whole information provided by the manufacturer.

This item is of particular interest as there is little information on the number of hours the VRF system works at partial load and how the VRF-SysCurve model of EnergyPlus reproduces the equipment performance for those conditions compared to performance curves provided by the manufacturer. The accuracy of the model when reproducing the performance of the equipment at partial load and different working temperatures plays a major role in the estimation of the building final energy consumption.

The second objective was to study how the VRF system performs in an office building under different climates by implementing the HVAC system design and the energy performance simulation in an Open BIM workflow. One of the main challenges of implementing the BIM methodology in the Spanish AEC industry is to make energy simulation of buildings available to project agents to support their decisions. 


\section{Materials and Methods}

VRF HVAC systems are typically composed of an outdoor unit (compressor) and several indoor units. The outdoor unit is normally outdoors and is responsible for cooling and heating the refrigerant that is sent through pipes to condition the building. The outdoor unit, normally cooled by air, has a variable speed compressor that provides a variable refrigerant flow and works more efficiently than conventional compressors of similar size. The ventilation air is usually delivered to the building by means of a dedicated outdoor air system (DOAS).

This section includes the description of the proposed method for calculating the performance of a VRF system. The improvement achieved with respect to the one available in EnergyPlus version 8.9 is quantified based on its ability to reproduce the experimental curves provided by the manufacturer.

The VRF HVAC system design and the energy simulation are integrated in an Open BIM workflow as a novel aspect of this work. The performance of a VFR system in an office building is then analysed under different climates by constructing the project with the information provided by specialized BIM applications that communicate with each other using IFC files.

\subsection{VRF System Model}

The design of a building HVAC system implies the knowledge of the performance curves of the commercial equipment that is to be installed. These curves (full-load and part-load capacity and Coefficient of Performance (COP) ratio) can be calculated from the information facilitated by the manufacturers of VRF equipment in the form of tables or graphs. The integration of these curves in software such as EnergyPlus allows us to reproduce the operation of the equipment, evaluate different design options and select the most suitable HVAC system from an energy point of view.

The performance curves determine the operation of the equipment in working conditions different from the nominal ones used for the design. VRF systems have proven to provide considerable energy savings for applications such as office buildings or hotels. One of the reasons is the ability of these systems to work continuously and efficiently at low partial loads, which is a common situation in these applications. Therefore, high efficiency at partial loads is a competitive advantage for manufacturers of VRF systems.

EnergyPlus version 8.9 contains a model of a VRF heat pump system based on its performance data. Only the relevant points of the model equations are explained in this paper, considering an air-to-air heat pump. The complete description of the model can be found in Reference [12], while the standard curve-fitting methodology for this model is available at [11].

The EnergyPlus VRF system curve based model calculates, among other results, the electric power consumed by the compressor in the outdoor unit to match the thermal demands of the building zones where the connected indoor units are placed.

The available cooling capacity of the outdoor unit at each time step $\left(\dot{\mathrm{Q}}_{\mathrm{c}, \mathrm{HP}}\right)$ is calculated by correcting the nominal cooling capacity of the device $\left(\dot{\mathrm{Q}}_{\mathrm{c}, \mathrm{HP}, \mathrm{nom}}\right)$ with several factors that can be obtained from manufacturer data (Equation (1)).

$$
\dot{\mathrm{Q}}_{\mathrm{c}, \mathrm{HP}}=\dot{\mathrm{Q}}_{\mathrm{c}, \mathrm{HP}, \text { nom }} \cdot \mathrm{CAPFT}_{\mathrm{c}, \mathrm{HP}} \cdot \mathrm{CR}_{\mathrm{c}, \mathrm{corr}}
$$

$\mathrm{CAPFT}_{\mathrm{c}, \mathrm{HP}}$ considers the effect of the average indoor air wet-bulb temperature $\left(\mathrm{T}_{\mathrm{wb}, \mathrm{avg}}\right)$ and of the outdoor air temperature $\left(\mathrm{T}_{\mathrm{con}}\right)$. CAPFT $\mathrm{C}_{\mathrm{c}, \mathrm{HP}}$ is obtained from manufacturer data by dividing the cooling capacity at the corresponding working temperatures by the nominal cooling capacity. These results can be input to the EnergyPlus model as a table or as a performance curve by fitting them to Equation (2).

$$
\mathrm{CAPFT}_{\mathrm{c}, \mathrm{HP}}=\mathrm{a}_{0}+\mathrm{a}_{1} \mathrm{~T}_{\mathrm{wb}, \mathrm{avg}}+\mathrm{a}_{2} \mathrm{~T}_{\mathrm{wb}, \mathrm{avg}}^{2}+\mathrm{a}_{3} \mathrm{~T}_{\mathrm{con}}+\mathrm{a}_{4} \mathrm{~T}_{\text {con }}^{2}+\mathrm{a}_{5} \mathrm{~T}_{\mathrm{wb}, \mathrm{avg}} \mathrm{T}_{\text {con }}
$$


$\mathrm{CR}_{\mathrm{c}, \mathrm{corr}}$ considers the increase in available capacity in case that the combination ratio of indoor units (CR) is larger than $100 \%$. CR is the total cooling capacity of connected indoor units divided by the nominal cooling capacity of the outdoor unit.

This maximum available cooling capacity of the outdoor unit $\dot{\mathrm{Q}}_{\mathrm{c}, \mathrm{HP}}$ is compared to the total cooling load to calculate the part-load ratio (PLR) of the compressor (Equation (3)). The total cooling load on the outdoor unit is the total capacity required by the indoor units $\left(\dot{\mathrm{Q}}_{\mathrm{c}, \mathrm{TU}}\right)$ plus the piping losses, which are considered in the model through a correction factor given by the manufacturers $\left(\mathrm{P}_{\mathrm{c}, \mathrm{corr}}\right)$.

$$
\mathrm{PLR}=\frac{\dot{\mathrm{Q}}_{\mathrm{c}, \mathrm{TU}}}{\dot{\mathrm{Q}}_{\mathrm{c}, \mathrm{HP}} \cdot \mathrm{P}_{\mathrm{c}, \mathrm{corr}}}
$$

The power consumed by the outdoor unit $\left(\dot{\mathrm{P}}_{\mathrm{c}}\right)$ is then calculated with Equation (4).

$$
\dot{\mathrm{P}}_{\mathrm{c}}=\left(\frac{\dot{\mathrm{Q}}_{\mathrm{c}, \mathrm{HP}, \text { nom }} \cdot \mathrm{CAPFT}_{\mathrm{c}, \mathrm{HP}}}{\mathrm{COP}_{\mathrm{c}, \text { nom }}}\right) \cdot \text { EIRFT }_{\mathrm{c}} \cdot \text { EIRFPLR }_{\mathrm{c}} \cdot \mathrm{HPRTF}
$$

$\mathrm{EIRFT}_{\mathrm{C}}$ considers the effect on the power input of the indoor and outdoor air temperatures. This factor is obtained by dividing the cooling EIR (energy input ratio, this is the inverse of the cooling COP ratio) at each pair of temperatures and at full load by the nominal cooling EIR. Similarly to the cooling capacity, these results can be input to the EnergyPlus model as a table or as a performance curve by fitting them to Equation (5).

$$
\text { EIRFT }_{c}=b_{0}+b_{1} T_{w b, a v g}+b_{2} T_{w b, a v g}^{2}+b_{3} T_{c o n}+b_{4} T_{c o n}^{2}+b_{5} T_{w b, a v g} T_{c o n}
$$

EIRFPLR $_{c}$ (Equation (6)) takes into account the effect of the PLR. This factor is obtained by dividing the power input at nominal temperature conditions and at a given PLR by the nominal power input at full load. Once again, these coefficients can be input to the EnergyPlus model as a table or as a performance curve by fitting them to Equation (6).

$$
\text { EIRFPLR }_{c}=c_{0}+c_{1} \text { PLR }+c_{2} \text { PLR }^{2}+c_{3} \text { PLR }^{3}
$$

Finally, HPRTF is the heat pump runtime fraction, which is an expression that takes into account the cycling losses of the compressor when it works below its minimum PLR.

The described VRF model allows for differentiating up to two regions in the capacity and EIR working maps, in case they cannot be fitted to a single polynomial. This feature results in an increase of accuracy when using performance curves. This means that both CAPFT and EIRFT can be expressed either with a data table or with two curves. During the simulation, the VRF model will choose which curve to use depending on the temperature conditions.

The equations for heating mode are analogue and allow for considering also the effect of frosting in the outdoor unit.

Manufacturer data of VRF systems usually contain more information than the one that can be considered with the described model parameters. For instance, Figure 1 shows the variation of the cooling COP ratio with respect to the nominal cooling $\mathrm{COP}$ ratio $\left(\mathrm{COP}_{\mathrm{c}} / \mathrm{COP}_{\mathrm{c}, \text { nom }}\right)$ as a function of the outdoor dry-bulb temperature $\left(15-40{ }^{\circ} \mathrm{C}\right)$ and the PLR. It compares the values obtained from the manufacturer's data with that obtained using the model equations of EnergyPlus version 8.9 for VRF systems. 


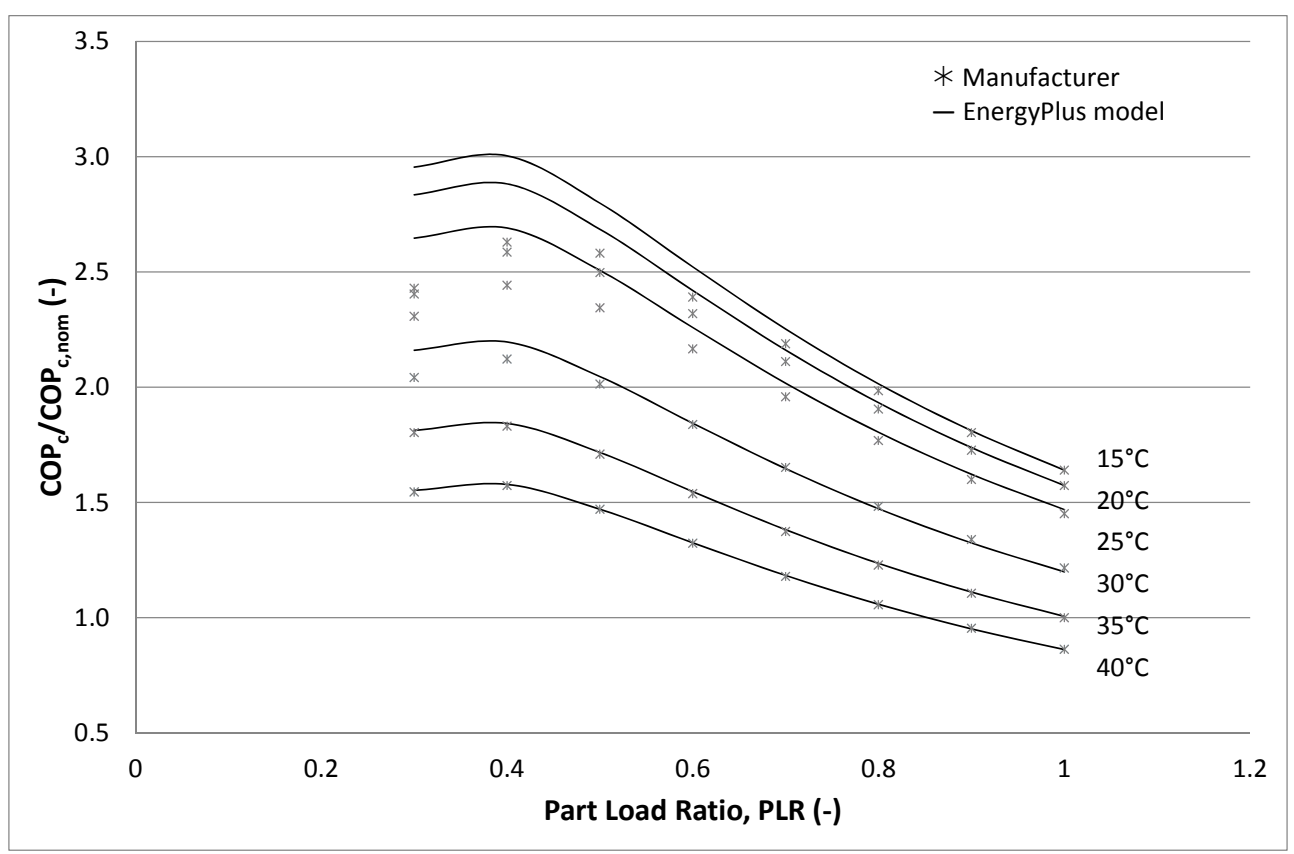

Figure 1. Variation of the cooling coefficient of performance (COP) ratio as a function of part load ratio and outdoor dry-bulb temperature (manufacturer and EnergyPlus variable refrigerant flow (VRF) model).

As can be observed according to the present manufacturer data set, the cooling COP ratio varies with the outdoor temperature and the PLR at the same time, especially at the low temperature and low PLR range. However, the EnergyPlus 8.9 VRF system curve based model requires as inputs one set of data for considering the effect of the temperature (EIRFT) and a different one for considering the effect of the PLR (EIRFPLR).

In the case of cooling mode, it is foreseeable that the equipment works with a low PLR when the outdoor temperature is also low. That is why the lack of adjustment shown in Figure 1 in the area of low outdoor temperatures and low PLRs is considered important in accurately forecasting the power consumption of the VRF equipment.

A new methodology for building the EnergyPlus VRF system model performance curves is proposed with the purpose of considering more accurately the whole data set of working points provided by the manufacturer.

The proposed method allows using the existing EnergyPlus VRF system curve based model. It consists in fitting directly the manufacturer power input data to Equation (4), instead of obtaining separately the performance curves in Equations (5) and (6) according to their definition.

In Equation (4), $\dot{\mathrm{Q}}_{\mathrm{c}, \mathrm{HP} \text {,nom, }} \mathrm{COP}_{\mathrm{c}, \text { nom }}$ ratio and $\mathrm{CAPFT}_{\mathrm{c}}$ are already determined by the manufacturer capacity data. The coefficient HPRTF equals 1 , since there are no cycling losses at the working region studied.

Therefore, the unknowns that can be used for fitting the power input data are the coefficients $b_{i}$ and $c_{i}$ of the polynomials in Equations (5) and (6), which results in Equation (7).

$$
\begin{gathered}
\dot{\mathrm{P}}_{\mathrm{c}}=\left(\frac{\dot{\mathrm{Q}}_{\mathrm{c}, \mathrm{HP}, \text { nom }} \cdot \mathrm{CAPFT}_{\mathrm{c}, \mathrm{HP}}}{\mathrm{COP} \mathrm{P}_{\mathrm{c}, \text { nom }}}\right) \\
\cdot\left(\mathrm{b}_{0}+\mathrm{b}_{1} \mathrm{~T}_{\mathrm{wb}, \mathrm{avg}}+\mathrm{b}_{2} \mathrm{~T}_{\mathrm{wb}, \mathrm{avg}}^{2}+\mathrm{b}_{3} \mathrm{~T}_{\mathrm{con}}+\mathrm{b}_{4} \mathrm{~T}_{\mathrm{con}}^{2}+\mathrm{b}_{5} \mathrm{~T}_{\mathrm{wb}, \text { avg }} \mathrm{T}_{\mathrm{con}}\right) \\
\cdot\left(\mathrm{c}_{0}+\mathrm{c}_{1} \mathrm{PLR}+\mathrm{c}_{2} \mathrm{PLR}^{2}+\mathrm{c}_{3} \mathrm{PLR}^{3}\right)
\end{gathered}
$$


A least squares technique is employed to fit the power input data into Equation (7), in order to obtain the coefficients $b_{i}$ and $c_{i}$. These coefficients are then used as inputs of the existing EnergyPlus VRF system curve based model, via the performance curves EIRFT and EIRFPLR.

This methodology can be extended to use the dual performance curve feature mentioned above, by splitting the power input map into two temperature regions and performing a different fitting for each one. This strategy provides more accurate results.

The methodology explained is analogue for the heating mode. A difference with the cooling mode is that, in the heating mode, the frosting and defrosting in the outdoor unit affects the system performance and must be considered. While the EnergyPlus VRF system model has inputs for defining in detail these processes, manufacturers usually do not provide such specific data. Instead, they usually provide values of integrated or mean heating capacity that include the defrosting periods. In this work, the integrated heating capacity values have been used to build the heating mode performance curves instead of the maximum heating capacity values, with the purpose of reproducing the loss in performance reported by the manufacturer regarding this fact.

\subsection{Model Verification}

Figure 2 compares the variation of the cooling $\mathrm{COP}$ ratio $\left(\mathrm{COP}_{\mathrm{c}} / \mathrm{COP}_{\mathrm{c}, \text { nom }}\right)$ obtained from the manufacturer's data with that obtained by the new curve fitting methodology for the EnergyPlus VRF system model.

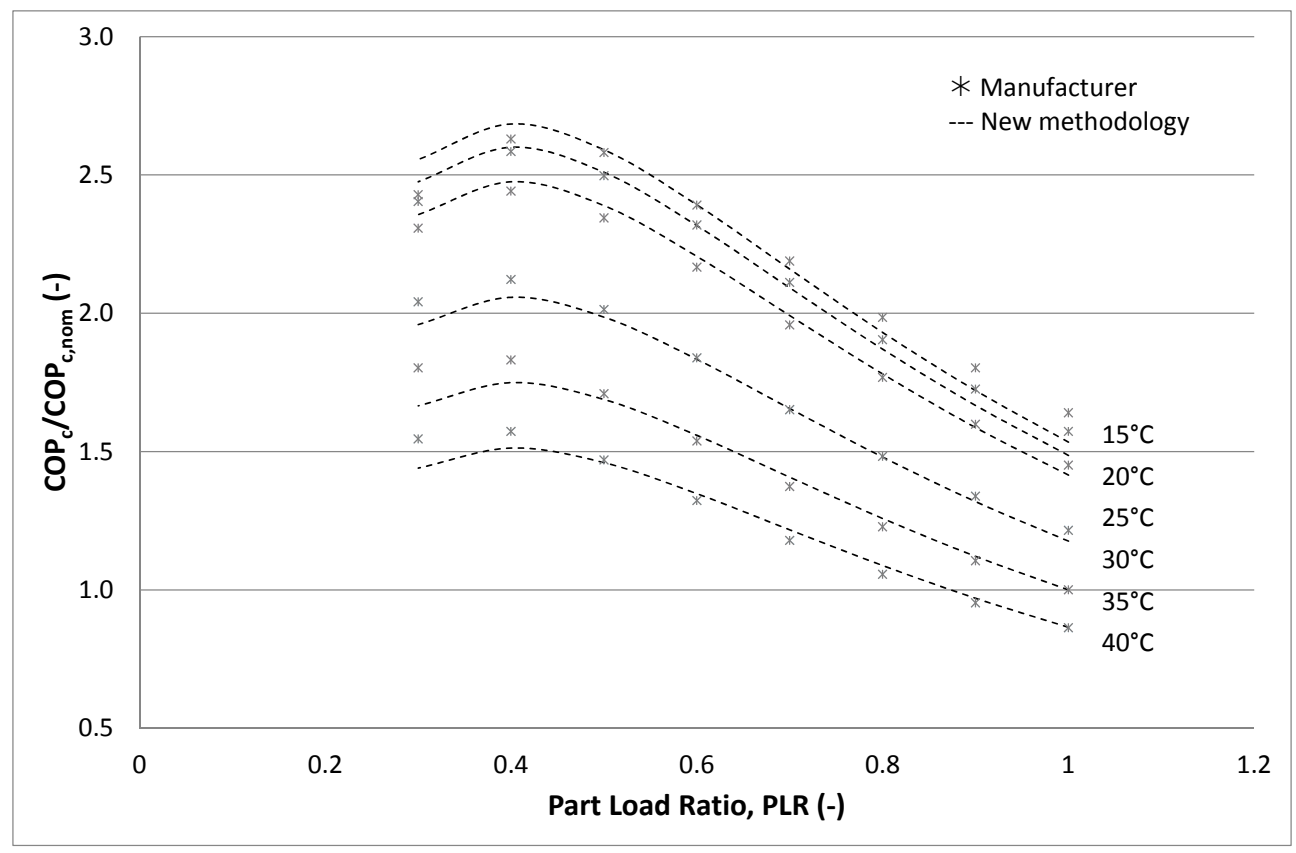

Figure 2. Variation of the cooling COP ratio as a function of part load ratio and outdoor dry-bulb temperature (manufacturer and EnergyPlus new model curves).

Qualitatively, the data provided by the new model curves is better adjusted to the data provided by the manufacturer than the data obtained with the standard model curves of EnergyPlus version 8.9 for VRF systems. Quantitatively, the RMSE was utilized for the comparison of manufacturer and predicted values. It is given by the following equation:

$$
\text { RMSE }=\sqrt{\frac{\sum_{j=1}^{N}\left(x_{j, m}-x_{j, s i m}\right)^{2}}{N}}
$$


where $\mathrm{N}$ is the number of data of the variable, $\mathrm{x}_{\mathrm{j}, \mathrm{m}}$ is the manufacturer value and $\mathrm{x}_{\mathrm{j}, \mathrm{sim}}$ is the predicted value.

The RMSE for the cooling COP ratio obtained with the standard model curves of EnergyPlus was 0.518 , while the RMSE for the cooling COP ratio obtained with the new model was 0.177 . This improvement in the prediction of the operation of the VRF system will have greater or lesser effect depending on the cooling demand of the building and therefore on the working conditions ( $T_{\text {out }}$, PLR) of the equipment.

Figure 3 compares the variation of the heating $\mathrm{COP}$ ratio $\left(\mathrm{COP}_{\mathrm{h}} / \mathrm{COP}_{\mathrm{h} \text {,nom }}\right)$ obtained from the manufacturer's data with that obtained using the standard model curves of EnergyPlus for VRF systems and the new implemented model curves. The effect of defrosting is included in both cases alike.

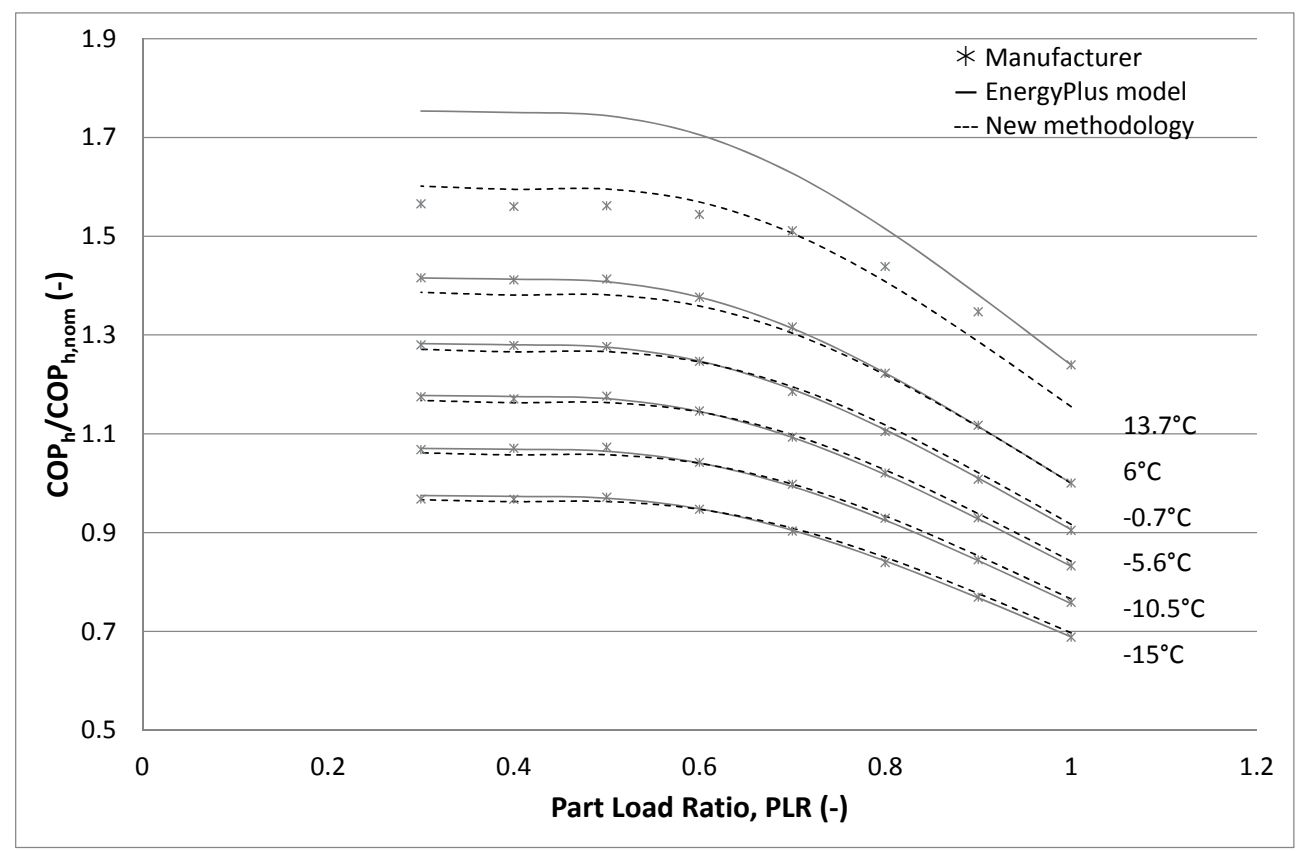

Figure 3. Variation of the heating COP ratio as a function of part load ratio and outdoor dry-bulb temperature (manufacturer and EnergyPlus standard and new model curves).

In this case, the RMSE for the heating COP ratio obtained with the standard model curves of EnergyPlus was 0.226 , while the RMSE for the heating COP ratio obtained with the new model curves was 0.018 . The divergence of both models with respect to the manufacturer's data is much less than in the case of cooling mode and only seems to affect the high temperature working range.

\subsection{Open BIM Workflow}

Figure 4 displays the Open BIM workflow. It is based on the use of specific software tools for each of the specialties that collaborate in a building project, which are able to share their results. This communication is done by means of open standard formats such as IFC, so that the data of the project does not depend on any specific software and any software developer can get into the workflow. In this way, the digital building model is developed progressively with the information defined by the team members. All the project information is stored on the BIMserver.center platform, which is a service to manage and share all the files of the project in the cloud [23]. 


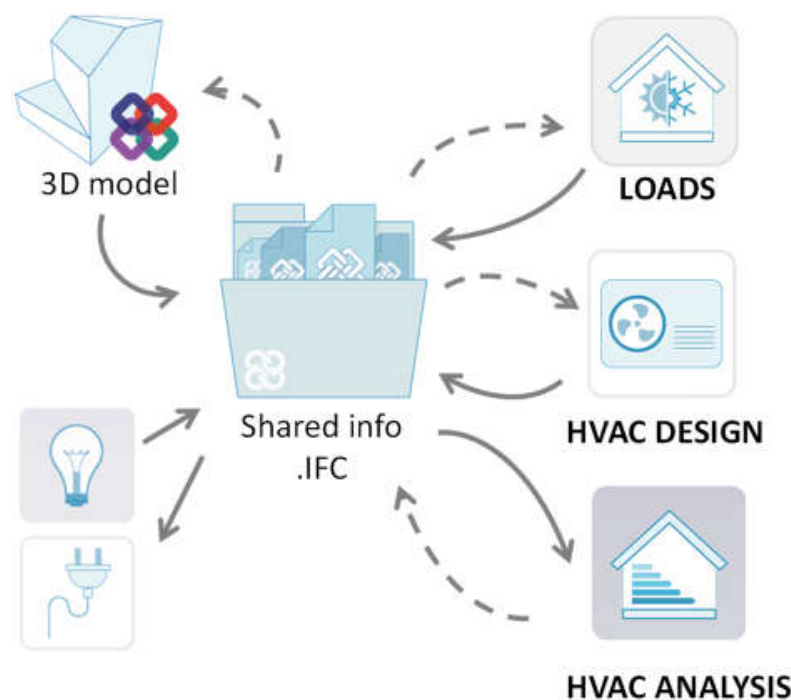

Figure 4. Open business information modelling (BIM) workflow.

This work focuses on the integration of the VRF system design and the building energy simulation into the proposed workflow. This task is divided into three steps: calculation of the thermal loads, sizing and design of the HVAC installation and energy simulation. Starting with a 3D model of the building which describes just its geometry, the information needed to perform each of these steps is provided by means of specialized BIM software tools.

Thanks to the Open BIM technology, the HVAC design workflow can interact with other specialties, such as lighting or acoustics. The data defined once in any program integrated in the workflow is then used in the others. This implies, for instance, that the HVAC system defined in a design and sizing program can become automatically ready for its simulation in EnergyPlus.

\subsection{Office Building Study}

The new methodology was used to analyse the performance of a VFR system in an office building under the climates of two Spanish cities: Madrid (D3) and Barcelona (C2). Each city in Spain is assigned with a climatic zone by the Spanish Building Technical Code (SBTC) [24] according to the severity of its climatic conditions in winter (A-most benign, E-most rigorous) and summer (1-most benign, 4-most rigorous). The hourly weather conditions of both cities were displayed on the psychrometric chart (Figure 5).

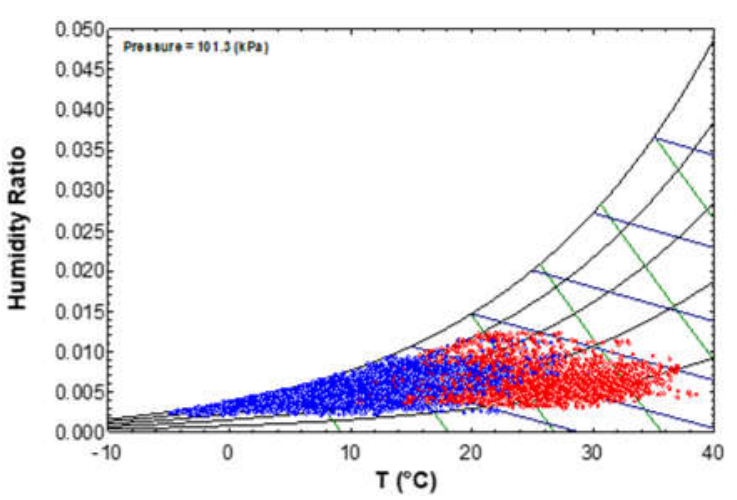

(a)

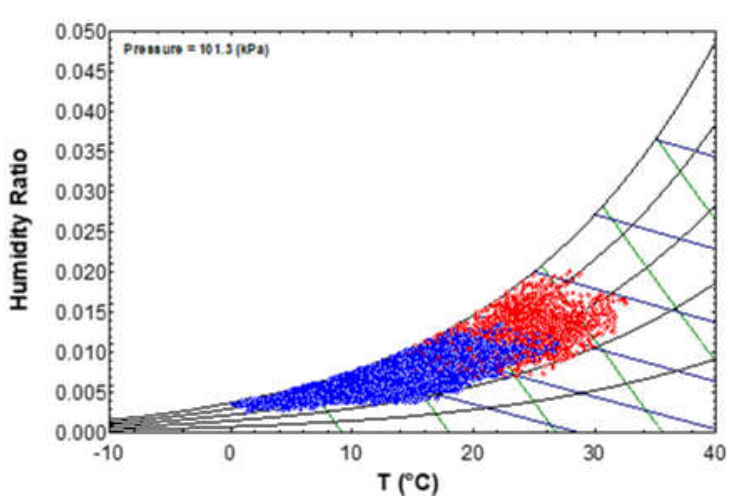

(b)

Figure 5. Weather conditions for (a) Madrid and (b) Barcelona. 
To verify the importance of the performance curves of the VRF systems in the estimation of the energy consumption, a $441 \mathrm{~m}^{2}$ office building was simulated located in Barcelona and Madrid (Figure 6).

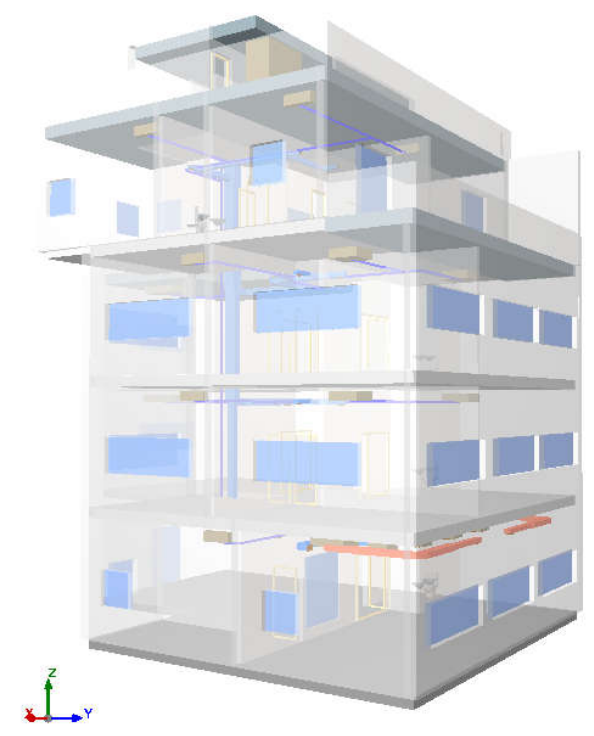

Figure 6. Office building 3D-model.

The building skin meets the requirements of the SBTC in terms of heating and cooling limitation of the energy demand. Table 1 indicates the U-values for the facade and roof of the office building. A heat transfer coefficient of $2 \mathrm{~W} / \mathrm{m}^{2} \mathrm{~K}$ and a solar gain factor of 0.75 were set for the windows.

Table 1. Heat transfer coefficients and energy demand.

\begin{tabular}{cccccccc}
\hline \multirow{2}{*}{ City } & $\begin{array}{c}\text { Climatic } \\
\text { Zone }\end{array}$ & $\begin{array}{c}\text { U-Ext. } \\
\text { Wall }\end{array}$ & U-Roof & $\begin{array}{c}\text { Heating } \\
\text { Demand }\end{array}$ & $\begin{array}{c}\text { Cooling } \\
\text { Demand }\end{array}$ & $\begin{array}{c}\text { Combined } \\
\text { Demand }\end{array}$ & $\begin{array}{c}\text { Limit } \\
\text { Demand }\end{array}$ \\
\cline { 2 - 8 } & $\mathbf{( \mathbf { W } / \mathbf { m } ^ { \mathbf { 2 } } \mathbf { K } )}$ & $\mathbf{( \mathbf { W } / \mathbf { m } ^ { \mathbf { 2 } } \mathbf { K } )}$ & $\mathbf{( \mathbf { k W h } / \mathbf { m } ^ { \mathbf { 2 } } \cdot \mathbf { y } )}$ & $\mathbf{( \mathbf { k W h } / \mathbf { m } ^ { \mathbf { 2 } } \cdot \mathbf { y } )}$ & $\mathbf{( \mathbf { k W h } / \mathbf { m } ^ { \mathbf { 2 } } \cdot \mathbf { y } )}$ & $\mathbf{( \mathbf { k W h } / \mathbf { m } ^ { \mathbf { 2 } } \cdot \mathbf { y } )}$ \\
\hline Barcelona & C2 & 0.57 & 0.32 & 10.8 & 25.9 & 28.9 & 33.4 \\
\hline Madrid & D3 & 0.48 & 0.29 & 20.6 & 34.9 & 45.0 & 55.9 \\
\hline
\end{tabular}

Table 1 indicates the heating and cooling demands of the office building in the cities of Madrid and Barcelona, along with the limits values fixed by the SBTC. The SBTC uses the combined heating and cooling energy demand to ensure compliance with the limitation of the building's energy demand. This combined energy demand is obtained as a weighted sum of the heating and cooling energy demands (Equation (9)).

$$
\text { Combined Demand }=\text { Heating Demand }+0.7 \text { Cooling Demand }
$$

The limit value of the demand is calculated as a percentage of the energy demand of a reference building, obtained from the building to be evaluated, with its same shape, size, orientation, interior zoning, use of each space and constructive solutions typified according to the climatic zone [24]. The internal gains (occupancy, lighting and equipment) were specified according to the SBTC as medium internal load $\left(7.5 \mathrm{~W} / \mathrm{m}^{2}\right)$ for $12 \mathrm{~h}$ non-residential uses. The ventilation system of the building consists of an outdoor air-handling unit which supplies fresh air at outdoor conditions to the occupied spaces of the building. The ventilation flow rate is set to 0.8 air changes per hour during the occupied hours. While the ventilation system is working, it is assumed that overpressure in the spaces avoids 
infiltration. Nevertheless, infiltration is considered in the energy simulation when the ventilation system is turned off, this is, during the unoccupied hours.

The application CYPETHERM LOADS, included in the Open BIM workflow was used to calculate the thermal load of the office building. This tool uses the ASHRAE radiant time series method and starts from the office building 3D model previously designed with the BIM software IFC Builder.

The VRF system was designed using the application CYPETHERM HVAC (CYPE Ingenieros S.A., Alicante, Spain), also integrated in the Open BIM workflow, which received the thermal loads calculated by CYPETHERM LOADS. An outdoor unit (OU) connected to 15 indoor units was selected to meet the energy demand of the building. Table 2 shows the nominal characteristics of this equipment.

Table 2. VRF nominal features.

\begin{tabular}{|c|c|c|c|c|}
\hline \multirow[t]{2}{*}{ Equipment } & \multicolumn{2}{|c|}{$\begin{array}{c}\text { Heating } \\
\left(\mathrm{T}_{\text {out }}=7^{\circ} \mathrm{C} \mathrm{db} / 6{ }^{\circ} \mathrm{C} \text { wb, } \mathrm{T}_{\text {int }}=20{ }^{\circ} \mathrm{C} \mathrm{db}\right)\end{array}$} & \multicolumn{2}{|c|}{$\begin{array}{c}\text { Cooling } \\
\left(\mathrm{T}_{\text {out }}=35^{\circ} \mathrm{C}, \mathrm{T}_{\text {int }}=27{ }^{\circ} \mathrm{C} \mathrm{db} / 19{ }^{\circ} \mathrm{C} \text { wb }\right)\end{array}$} \\
\hline & $\dot{\mathrm{Q}}_{\mathrm{h}, \text { nom }}(\mathrm{kW})$ & $\mathrm{COP}_{h, \text { nom }}$ ratio & $\dot{\mathrm{Q}}_{\mathrm{c}, \text { nom }}(\mathrm{kW})$ & $\mathrm{COP}_{\mathrm{c}, \text { nom }}$ ratio \\
\hline OU & 31.5 & 4.25 & 28 & 3.64 \\
\hline
\end{tabular}

Figure 7 shows a diagram of the VRF system.

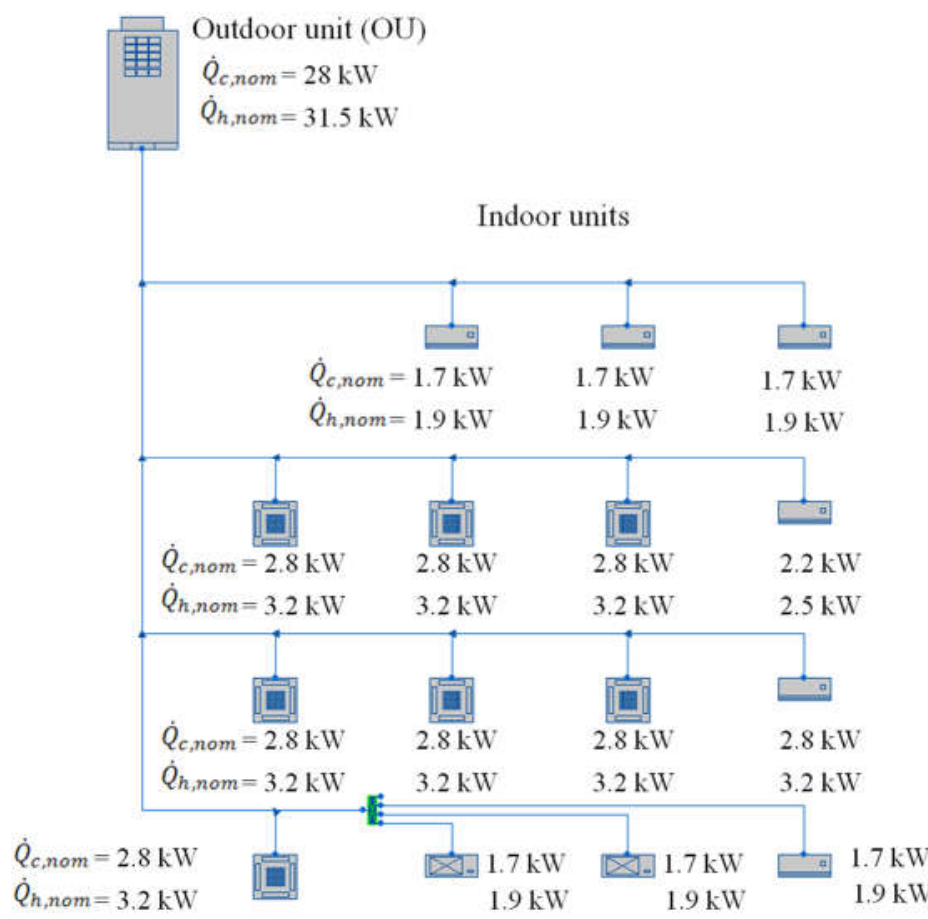

Figure 7. VRF Outdoor and Indoor Units.

The annual energy performance of the office building was calculated with CYPETHERM HE Plus, a BIM user interface for EnergyPlus 8.9 that contains the VRF system model developed in this paper. Thanks to the Open BIM workflow, the VRF system already defined using CYPETHERM HVAC can be directly imported into EnergyPlus.

\section{Results and Discussion}

The energy demand of the office building is lower than the limit fixed by the SBTC for the climates of Madrid and Barcelona (Table 1). The monthly thermal demands of the office building are displayed in Figure 8. 


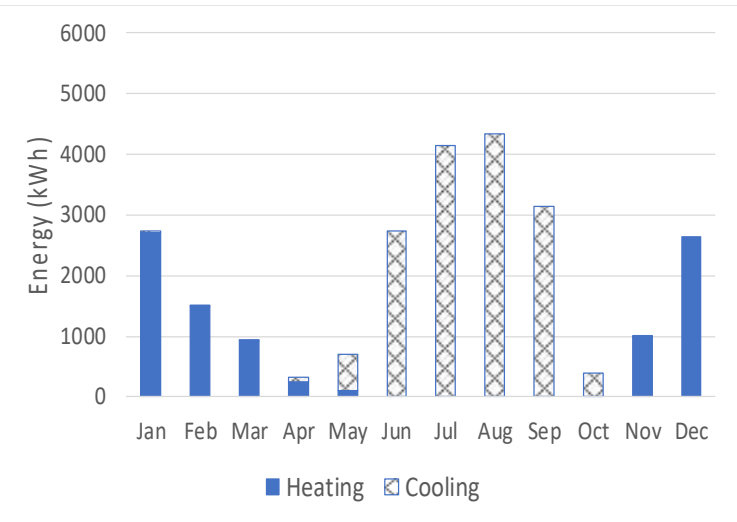

(a)

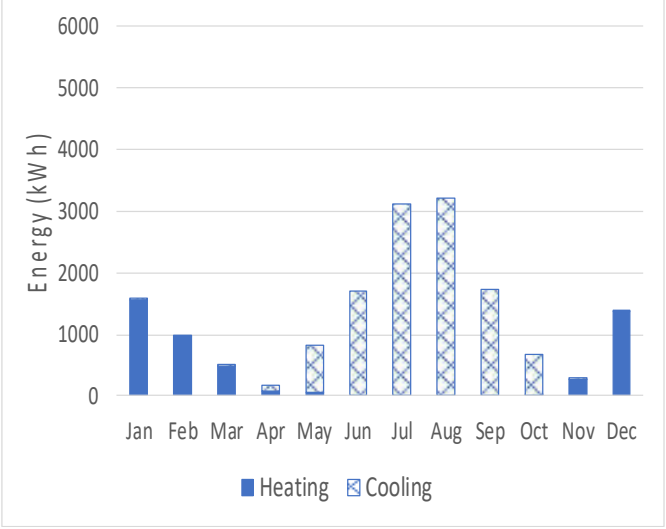

(b)

Figure 8. Heating and cooling energy demand for (a) Madrid and (b) Barcelona.

Unlike residential buildings in which the thermal load is determined mostly by weather conditions, in commercial buildings the demand for energy is also conditioned by internal loads. As can be seen in Figure 5 and Table 1, the mild coastal climate of Barcelona shows moderate heating $\left(10.8 \mathrm{kWh} / \mathrm{m}^{2} \cdot \mathrm{y}\right)$ and cooling loads $\left(25.9 \mathrm{kWh} / \mathrm{m}^{2} \cdot \mathrm{y}\right)$. The continental temperate climate of Madrid with hot summers (temperatures over $35^{\circ} \mathrm{C}$ ) and cool winters (temperatures as low as $-5^{\circ} \mathrm{C}$ ) shows significant cooling $\left(34.9 \mathrm{kWh} / \mathrm{m}^{2} \cdot \mathrm{y}\right)$ and heating demand $\left(20.6 \mathrm{kWh} / \mathrm{m}^{2} \cdot \mathrm{y}\right)$.

Figure $9 \mathrm{a}, \mathrm{b}$ show the histogram with the percentage of hours that the VRF system works at partial load (cooling) grouped into outdoor temperature ranges for the cities of Madrid and Barcelona. There is a high percentage of working hours at moderate outside temperatures and part load ratios under 0.5 , which corresponds to the area of Figure 1 in which there was a greater deviation between the values predicted by the standard EnergyPlus VRF model and the values supplied by the manufacturer.

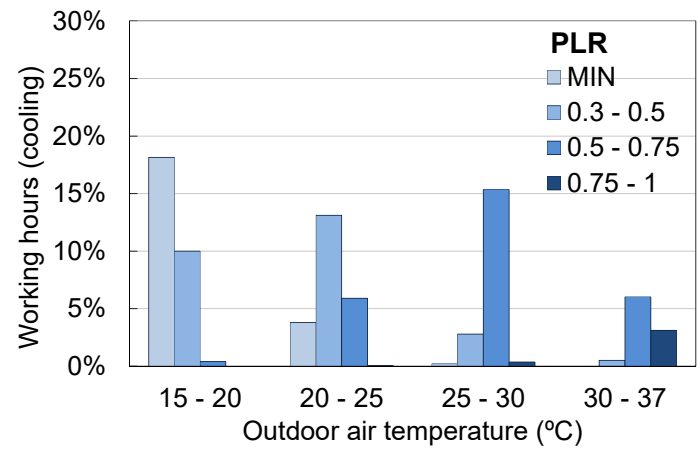

(a)

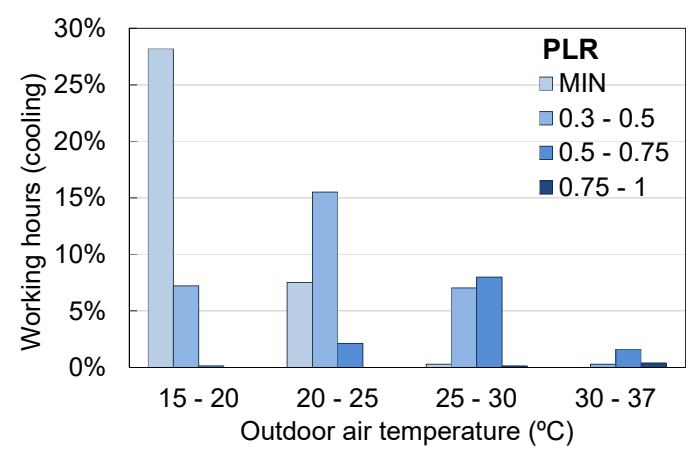

(b)

Figure 9. Working hours at partial load (cooling) grouped into outdoor temperature ranges for Madrid (a) and Barcelona (b).

Table 3 displays the percentage deviation between the electric energy consumption estimated by the standard EnergyPlus VRF model and the energy consumption estimated by the new model curves. 
Table 3. Estimation of electric energy consumption with the standard and new model curves.

\begin{tabular}{|c|c|c|c|c|c|c|}
\hline & \multicolumn{3}{|c|}{$\begin{array}{c}\text { VRF Electric Consumption (kWh) } \\
\text { Madrid }\end{array}$} & \multicolumn{3}{|c|}{$\begin{array}{l}\text { VRF Electric Consumption (kWh) } \\
\text { Barcelona }\end{array}$} \\
\hline & $\begin{array}{l}\text { Standard } \\
\text { Model }\end{array}$ & New Model & Difference & $\begin{array}{l}\text { Standard } \\
\text { Model }\end{array}$ & New Model & Difference \\
\hline Cooling & 2263 & 2337 & $+3.27 \%$ & 1480 & 1582 & $+6.91 \%$ \\
\hline Heating & 1425 & 1439 & $+0.97 \%$ & 711 & 722 & $+1.59 \%$ \\
\hline
\end{tabular}

As expected, the consumption increases with the new model curves. In fact, Figure 2 shows that the new model predicts lower cooling COP ratios for moderate outside temperatures (between $15^{\circ} \mathrm{C}$ and $25^{\circ} \mathrm{C}$ ) and part load ratios under 0.5 than the cooling COP ratios predicted by the standard EnergyPlus VRF model curves. They are also more in line with the values provided by the manufacturer. In the case of Barcelona, where the number of hours working in this area increases, the difference in the predicted energy consumption is greater than in Madrid.

The use of VRF systems can significantly reduce energy consumption compared to other HVAC systems. Table 4 shows the annual non-renewable source energy consumption of the VRF system broken down into heating, cooling and lighting for the cities of Madrid and Barcelona. To calculate the values of source energy included in Table 4, a primary energy factor of 1.954 was considered for electrical energy [25].

Table 4. Primary energy consumption, $\mathrm{CO}_{2}$ emissions and building energy classification.

\begin{tabular}{cccccccc}
\hline \multirow{2}{*}{ City } & \multicolumn{4}{c}{$\mathrm{E}_{\mathrm{s}, \mathbf{n r}}\left(\mathbf{k W h} / \mathbf{m}^{2} / \mathbf{y}\right)$} & \multicolumn{3}{c}{$\mathrm{CO}_{2}$ Emissions $\left(\mathbf{k g ~} \mathrm{CO}_{2} / \mathbf{m}^{2} / \mathbf{y}\right)$} \\
\cline { 2 - 9 } & Heating & Cooling & Lighting & Total & Building & Class B & Class \\
\hline Barcelona & 3.2 & 7.02 & 55.6 & 65.8 & 11.2 & $15.7-25.5$ & $\mathrm{~A}$ \\
\hline Madrid & 6.4 & 10.4 & 55.6 & 72.4 & 12.3 & $19.3-31.4$ & $\mathrm{~A}$ \\
\hline \multicolumn{4}{c}{$\mathrm{E}_{\mathrm{s}, \mathrm{nr}}$ is the primary energy consumption. }
\end{tabular}

In energy classification of buildings, Class A stands for low energy consumption and G stands for high. The SBTC establishes that the energy rating of a commercial building must be equal to or greater than class $\mathrm{B}$. Table 4 contains the $\mathrm{CO}_{2}$ emissions limits that define class $\mathrm{B}$ as a function of the climatic zone. It also shows the total $\mathrm{CO}_{2}$ emissions $\left(\mathrm{kg} \mathrm{CO}_{2} / \mathrm{m}^{2} / \mathrm{y}\right)$ and the building energy performance classification.

It can be seen how energy performance class of the analysed building is $\mathrm{A}$, the maximum in energy classification of buildings. The $\mathrm{CO}_{2}$ emissions are always lower than the lower limit of the range that defines class $\mathrm{B}$.

For the energy performance of commercial Nearly Zero-Energy Building (NZEB) (offices) the benchmarks proposed by EU [6] are $20-30 \mathrm{kWh} /\left(\mathrm{m}^{2} . \mathrm{y}\right)$ of net primary energy for the Mediterranean climatic zone (with $80-90 \mathrm{kWh} /\left(\mathrm{m}^{2} . \mathrm{y}\right)$ of primary energy use covered by $60 \mathrm{kWh} /\left(\mathrm{m}^{2} . \mathrm{y}\right)$ of on-site renewable sources) and $40-55 \mathrm{kWh} /\left(\mathrm{m}^{2} . \mathrm{y}\right)$ of net primary energy for the Continental climatic zone (with $85-100 \mathrm{kWh} /\left(\mathrm{m}^{2} . \mathrm{y}\right)$ of primary energy use covered by $45 \mathrm{kWh} /\left(\mathrm{m}^{2} . \mathrm{y}\right)$ of on-site renewable sources).

The primary energy consumption of the analysed building equipped with a VRF HVAC system ranges between a minimum of $65.8 \mathrm{kWh} /\left(\mathrm{m}^{2} \cdot \mathrm{y}\right)$ for the Mediterranean climate of Barcelona and a maximum of $72.4 \mathrm{kWh} /\left(\mathrm{m}^{2} \cdot \mathrm{y}\right)$ for the Continental climate of Madrid. These values would be within the ranges proposed by EU [6] if measures were implemented that would reduce the demand for lighting (daylight-responsive artificial light control system) or renewable energies were implied that would contribute the differential of $15-30 \mathrm{kWh} /\left(\mathrm{m}^{2} \cdot \mathrm{y}\right)$ in Madrid and $35-45 \mathrm{kWh} /\left(\mathrm{m}^{2} \cdot \mathrm{y}\right)$ in Barcelona (photovoltaic system). 


\section{Conclusions}

The objectives of this work were to develop a more precise model of the VRF system than the one available in EnergyPlus version 8.9 and to study the operation of this system in an office building under Mediterranean and Continental climates by implementing the building energy simulation in an Open BIM workflow.

The new model curves adjusted better to the data provided by the manufacturer than the data obtained with the standard model curves of EnergyPlus version 8.9 for VRF systems. The RMSE for the cooling COP ratio obtained with the standard model curves of EnergyPlus was 0.518, while the RMSE for the cooling COP ratio obtained with the new model was 0.177.

This improvement in the prediction of the operation of the VRF system had greater effect in the case of Barcelona because the VRF system worked a high percentage of hours at moderate outside temperatures and part load ratios under 0.5. The deviation between the values predicted by the standard EnergyPlus VRF model and the values supplied by the manufacturer was especially significant.

The percentage deviation between the estimation of the electric energy consumption with the standard and the new models was of $6.91 \%$ and $1.59 \%$ for cooling and heating respectively in the case of Barcelona and of $3.27 \%$ and $0.97 \%$ respectively in the case of Madrid. As expected, the consumption increases with the new model curves.

The energy performance class of the analysed building was A, the maximum established by the SBTC. The primary energy consumption of the office building equipped with the VRF system was of $65.8 \mathrm{kWh} /\left(\mathrm{m}^{2} \cdot \mathrm{y}\right)$ for the Mediterranean climate of Barcelona and $72.4 \mathrm{kWh} /\left(\mathrm{m}^{2} \cdot \mathrm{y}\right)$ for the Continental climate of Madrid. These values would be within the ranges proposed by EU [6] if the demand for lighting would be reduced or renewable energies would provide the differential of $15-30 \mathrm{kWh} /\left(\mathrm{m}^{2} \cdot \mathrm{y}\right)$ in Madrid and $35-45 \mathrm{kWh} /\left(\mathrm{m}^{2} \cdot \mathrm{y}\right)$ in Barcelona.

Therefore, the simulation of the working conditions of the VRF system and the improvement of the EnergyPlus model to better consider the information provided by the manufacturer has proven to play a major role in the estimation of the building energy consumption.

The integration of the building energy simulation in an Open BIM workflow has also confirmed to be a useful instrument for design evaluation and certification of buildings. The project is constructed progressively with the information provided by specialized BIM applications (thermal loads, HVAC system and energy analysis) that communicate with each other using IFC files.

As mentioned in the introduction section, one of the main challenges of implementing the BIM methodology in the Spanish AEC industry is to make energy simulation of buildings available to project agents to support their decisions.

Once the process of being adopted by the Spanish Public Administrations as a tool for energy efficiency certification of buildings has been overcome, it is necessary to continue working on the improvement of the interface and the HVAC system models that integrate EnergyPlus [26]. Last but not least is the need for training to architects and engineers in university graduate and postgraduate courses.

Author Contributions: B.T.J. and P.J.M. designed the paper; B.T.J., B.G. and G.P.B. implemented the aerothermal heat pump model; B.T.J. and P.J.M. analysed the data and wrote the paper.

Funding: This research was funded by MINECO/AEI/FEDER,UE grant number [ENE2017-83729-C3-1-R].

Acknowledgments: The authors wish to acknowledge MINECO/AEI/FEDER,UE for financial support through Project ENE2017-83729-C3-1-R, which also provides the funds for covering the costs to publish in open access.

Conflicts of Interest: The authors declare no conflict of interest. 


\section{Abbreviations}

$\begin{array}{ll}\text { Nomenclature } & \\ \text { COP } & \text { Coefficient Of Performance, ratio (-) } \\ \text { CR } & \text { Combination ratio of indoor VRF units (-) } \\ \text { E } & \text { Energy (J) } \\ \text { EIR } & \text { Energy Input Ratio (1/COP) } \\ \dot{P} & \text { Power input (W) } \\ \text { PLR } & \text { Part load ratio (-) } \\ \text { Q } & \text { Heat pump capacity (W) } \\ \text { T } & \text { Temperature }\left({ }^{\circ} \text { C) }\right. \\ \text { Abbreviations } & \\ \text { BIM } & \text { Building Information Modelling } \\ \text { DHW } & \text { Domestic Hot Water } \\ \text { EPBD } & \text { Energy Performance of Buildings Directive } \\ \text { HVAC } & \text { Heating, Ventilating and Air Conditioning } \\ \text { NZEB } & \text { Nearly Zero-Energy Building } \\ \text { RMSE } & \text { Root Mean Square Error } \\ \text { SBTC } & \text { Spanish Building Technical Code } \\ \text { Subscripts } & \\ \text { avg } & \text { Average } \\ \text { c } & \text { Cooling } \\ \text { con } & \text { Condenser } \\ \text { corr } & \text { Correction factor } \\ \text { h } & \text { Heating } \\ \text { HP } & \text { Heat pump } \\ \text { nom } & \text { Nominal } \\ \text { nr } & \text { non-renewable } \\ \text { s } & \text { source } \\ \text { TU } & \text { Terminal units } \\ \text { wb } & \text { Wet bulb } \\ & \end{array}$

\section{References}

1. E.Y.T.E. (IDAE, Instituto para la diversificación y Ahorro de la Energía); Ministerio de Industria. Consumos del sector residencial en España Resumen de Información Básica; Ministerio de Industria: Madrid, Spain, 2014; pp. 1-16.

2. EU. Directive 2010/31/EU of the European Parliament and of the Council of 19 May 2010 on the energy performance of buildings (recast). Off. J. Eur. Union 2010, 13-35. [CrossRef]

3. Nardi, I.; Lucchi, E.; de Rubeis, T.; Ambrosini, D. Quantification of heat energy losses through the building envelope: A state-of-the-art analysis with critical and comprehensive review on infrared thermography. Build. Environ. 2018, 146, 190-205. [CrossRef]

4. Afify, R. Designing VRF systems. ASHRAE J. 2008, 50, 52-55.

5. Pezzutto, S.; De Felice, M.; Fazeli, R.; Kranzl, L.; Zambotti, S. Status Quo of the Air-Conditioning Market in Europe: Assessment of the Building Stock. Energies 2017, 10, 1253. [CrossRef]

6. EU Commission. Commision Recommendation (EU) 2016/1318 guidelines for the promotion of nZEB. Off. J. Eur. Union 2016, 208, 46-56.

7. Moran, P.; Goggins, J.; Hajdukiewicz, M. Super-insulate or use renewable technology? Life cycle cost, energy and global warming potential analysis of nearly zero energy buildings (NZEB) in a temperate oceanic climate. Energy Build. 2017, 139, 590-607. [CrossRef]

8. Sarbu, I.; Sebarchievici, C. Performance Evaluation of Radiator and Radiant Floor Heating Systems for an Office Room Connected to a Ground-Coupled Heat Pump. Energies 2016, 9, 228. [CrossRef]

9. Lucchi, M.; Lorenzini, M.; Valdiserri, P. Energy performance of a ventilation system for a block of apartments with a ground source heat pump as generation system. J. Phys. Conf. Ser. 2017, 796, 12034. [CrossRef] 
10. Aynur, T.N.; Hwang, Y.; Radermacher, R. Simulation comparison of VAV and VRF air conditioning systems in an existing building for the cooling season. Energy Build. 2009. [CrossRef]

11. Raustad, R. A variable refrigerant flow heat pump computer model in energyplus. In Proceedings of the ASHRAE Annual Meeting, Dallas, TX, USA, 30 January 2013; pp. 299-308.

12. US Department of Energy (DOE). EnergyPlusTM version 8.9.0 Documentation: Engineering Reference. 2018. Available online: www.energyplus.net (accessed on 21 December 2018).

13. Sharma, C.; Raustad, R. Compare energy use in variable refrigerant flow heat pumps field demostration and compter model. In Proceedings of the ASHRAE Annual Conference, Denver, CO, USA, 22-26 June 2013.

14. Hong, T.; Sun, K.; Zhang, R.; Hinokuma, R.; Kasahara, S.; Yura, Y. Development and validation of a new variable refrigerant flow system model in EnergyPlus. Energy Build. 2016, 117, 399-411. [CrossRef]

15. Kim, D.; Cox, S.J.; Cho, H.; Im, P. Evaluation of energy savings potential of variable refrigerant flow (VRF) from variable air volume (VAV) in the U.S. climate locations. Energy Rep. 2017, 3, 85-93. [CrossRef]

16. Yu, X.; Yan, D.; Sun, K.; Hong, T.; Zhu, D. Comparative study of the cooling energy performance of variable refrigerant flow systems and variable air volume systems in office buildings. Appl. Energy 2016, 183, 725-736. [CrossRef]

17. Kani-Sanchez, C.; Richman, R. Incorporating variable refrigerant flow (VRF) heat pump systems in whole building energy simulation-Detailed case study using measured data. J. Build. Eng. 2017, 12, 314-324. [CrossRef]

18. Kim, D.; Cox, S.J.; Cho, H.; Im, P. Model calibration of a variable refrigerant flow system with a dedicated outdoor air system: A case study. Energy Build. 2018, 158, 884-896. [CrossRef]

19. Candelario-Garrido, A.; García-Sanz-Calcedo, J.; Reyes Rodríguez, A.M. A quantitative analysis on the feasibility of 4D Planning Graphic Systems versus Conventional Systems in building projects. Sustain. Cities Soc. 2017, 35, 378-384. [CrossRef]

20. Olawumi, T.O.; Chan, D.W.M. Identifying and prioritizing the benefits of integrating BIM and sustainability practices in construction projects: A Delphi survey of international experts. Sustain. Cities Soc. 2018, 40, 16-27. [CrossRef]

21. European Parliament and the Council of the European Union. Directive 2014/24/EU of the European Parliament and the Council. Off. J. Eur. Union 2014, 2014, 65-242. [CrossRef]

22. Sattary, S.; Thorpe, D. Potential carbon emission reductions in australian construction systems through bioclimatic principles. Sustain. Cities Soc. 2016, 23, 105-113. [CrossRef]

23. CYPE Software. BIMserver.center-Workflow demo. 2018. Available online: https://www.youtube.com/ watch?v=T5uKMiIBn_c\&list=PLbM0_0AnNRm_NyVE0Rfev7aHs3DUww9iz\&index=18 (accessed on 21 December 2018).

24. CTE. Spanish Building Technical Code, Real Decreto 314/2006 17 Marzo. Agencia Estatal Boletín Oficial del Estado, 2006. Available online: https:/ / www.boe.es/buscar/act.php?id=BOE-A-2006-5515 (accessed on 21 December 2018).

25. IDEA. Factores de emisión de co2 y coeficientes de paso a energía primaria de diferentes fuentes de energía final consumidas en el sector de edificios en España. 2014. Available online: https:/ / energia.gob.es/es-es/ Paginas/index.aspx (accessed on 21 December 2018).

26. Torregrosa-Jaime, B.; González, B.; Martínez, P.J.; Payá-Ballester, G. Analysis of the Operation of an Aerothermal Heat Pump in a Residential Building Using Building Information Modelling. Energies 2018, 6, 1642. [CrossRef]

(C) 2018 by the authors. Licensee MDPI, Basel, Switzerland. This article is an open access article distributed under the terms and conditions of the Creative Commons Attribution (CC BY) license (http://creativecommons.org/licenses/by/4.0/). 